\title{
Examination and Conservation of Helal El-Beah Mosque, Dakahlia, Egypt
}

\author{
Nabil A. Bader1', Ragab Abu El-Hassan² \\ ${ }^{1}$ Conservation Department, Faculty of Archaeology, South Valley University, Qena, Egypt \\ ${ }^{2}$ Misr University for Science \& Technology (MUS), Conservation Department, Giza, Egypt \\ Email: nabil.abdeltawab@arch.svu.edu.eg
}

Received 11 February 2016; accepted 1 May 2016; published 4 May 2016

Copyright (C) 2016 by authors and Scientific Research Publishing Inc.

This work is licensed under the Creative Commons Attribution International License (CC BY). http://creativecommons.org/licenses/by/4.0/

(c) (i) Open Access

\begin{abstract}
Helal El-Beah mosque in Egypt was built from many different materials as sandstone, bricks and marble. These building materials were in a bad condition due to many degradation factors, mainly ground water and salt weathering, so many deterioration phenomena were appeared as horizontal and vertical cracks, salts, loss of the Islamic decorations in the façade and mihrab (Prayer niche), detachment of the plaster, biological colonization and featured dark of the stone surface. Prior to the conservation intervention, the building materials were characterized to identify their components. Scientific conservation treatment was carried out for the long-term conservation of the mosque. Conservation operations at the mosque included: repairing and roof insulation, wet and dry cleaning, joining of cracked parts and surface consolidating, replacement of the Portland cement plaster with lime plaster, re-cladding the lower part of the interior brick walls with sandstone tiles, replacement and completion of the stone blocks.
\end{abstract}

\section{Keywords}

Islamic Decoration, Brick, Sandstone, Conservation, Helal El-Beah Mosque, Salts Reduction, Completion, Re-Cladding

\section{Introduction}

\subsection{Brief History and Architectural Background}

The Mosque of Helal El-Beah was erected in $1270 \mathrm{AH}$ "as shown in the founding inscription on top of the stone entrance (Figure 1(a))” by Hilal Abdullah Hilal, one of notables of MitGhamr, Dakahlia Governorate, he was very rich, served as mayor and knew with El-Beah. Visitors and worshipers enter the mosque through a tall portal that is itself a work of art. It consists of rectangular entrance topped with straight threshold (architrave) inscribed 

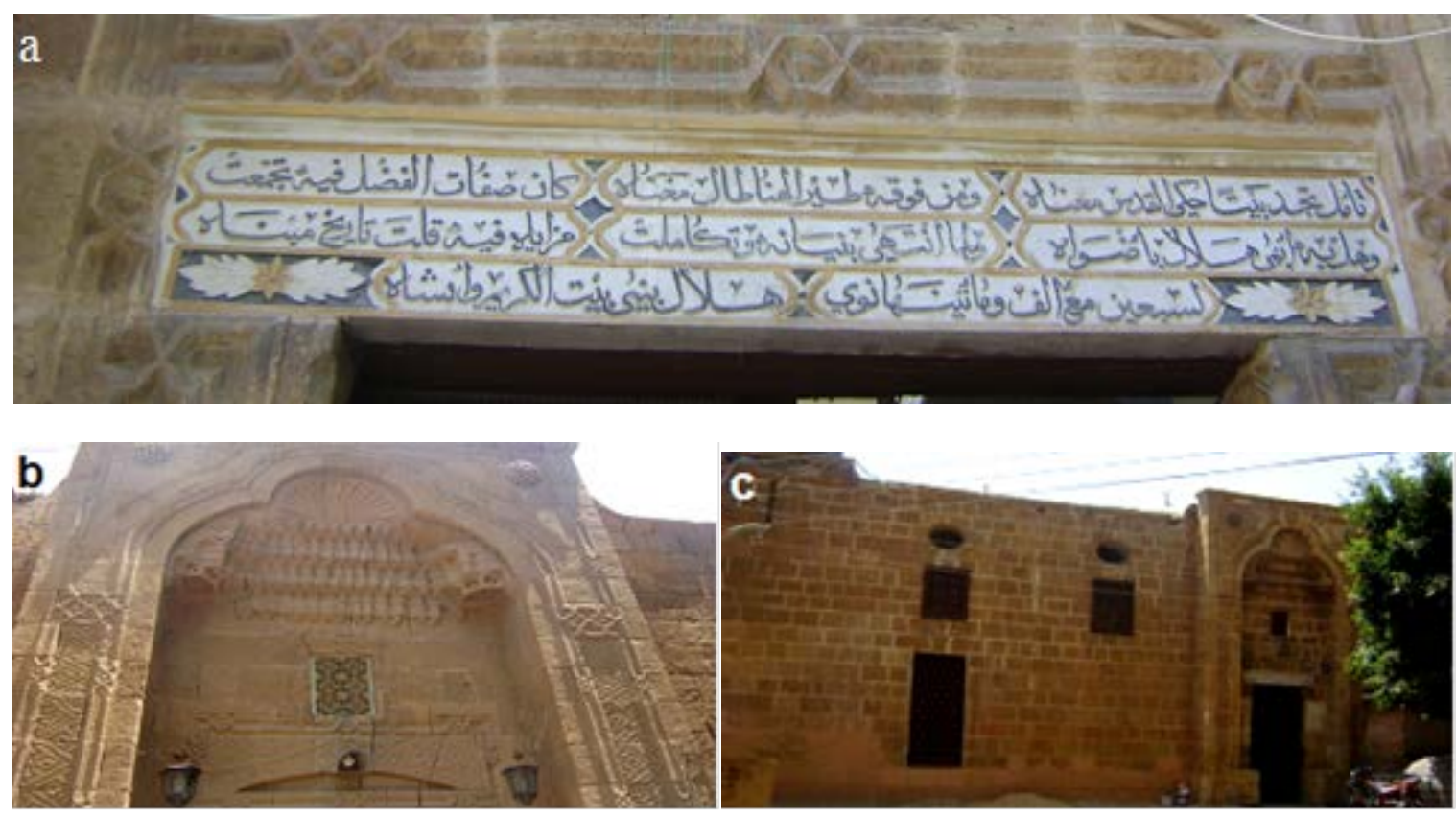

Figure 1. The façade of Helal Mosque. a-Founding text shows the erection and the date of the mosque erection; b-The tall portal of the mosque with Islamic decoration; c-The rest of the façade of the mosque.

with founding inscription written by Persian Nastaliq font (one of the fonts that written by it on Islamic buildings during the nineteenth century), it is true part as archaeological terms. Polygon (stellar dish) which consisted of six heads, halves and quarters of this Polygon decorated the upper part of the relieving arch and its spandrels. The door lintel, relieving arch and Nafis were surrounded with Player Fret (Geft) with six-memes, above the player fret, slot rectangular window covered with wooden decorations consisted of Polygon (stellar dish) that was uniquely carried out in kind and surrounded by player fret with the six-party memes. The entrance of the mosque culminated by trefoiled arch bases on five rows of stalactites was surrounded by player frit with six-party memes forms. The player frit tires on both sides of the main entrance contented Mafruk decorations, (known as decorative element in the Ottoman era and nineteenth century) which carried out by sunken relief (Figure 1(b)). As for the rest of the façade, it is clade with stone tiles punctuated by a secondary rectangular entrance topped by lintel, Nafis and relieving arch surrounded by player frit with a six-memes. At higher side entrance, there are two windows covered with wood cone substratum of a polygon form topped with two circular windows (Figure 1(c)). Figure 2 and Figure 3 show architecture plan of the façade and its Islamic decoration. The interior plan of this mosque looks like the Ottoman mosques that prevailed in Egyptian territories; it consists of rectangular space 12 $\times 15 \mathrm{~m}$, divided into three arcades by two rows of marble columns with different crowns carrying semi-circular arches contracts with each other and the walls by wooden boarding joist and the ceiling covered with wooden boarding joist. According to different analytical studies, the mosque was built of three types of raw materials: sandstone at external wall, bricks at internal wall and the columns were cut from marble (Figure 4). Lime mortar was used as joint mortar and plaster. The mosque suffered severe effect, some of them were collapsed (totally or partially) and several damage patterns were observed. The aim of this work is to study the building materials of the mosque to identify its components, the causes of damage that affect these materials, lead to several forms of deterioration, and introduce a scientific study for architectural and fine treatment.

\subsection{Current State}

Unfortunately, the preservation environment surrounding the building materials at the El-Helal mosque has attempted to encourage the weathering procedure, debilitating the stones and brick and threatening its structural stability. The façade of the mosque shows some clear indications of yielding cracks (Figure 5(a)) and partial collapse at several locations because of the physiochemical and architectural effects of deterioration factors. Collapse of large parts of the ceiling of the mosque, especially north arcade (Figure 5(b)) was one of the important 


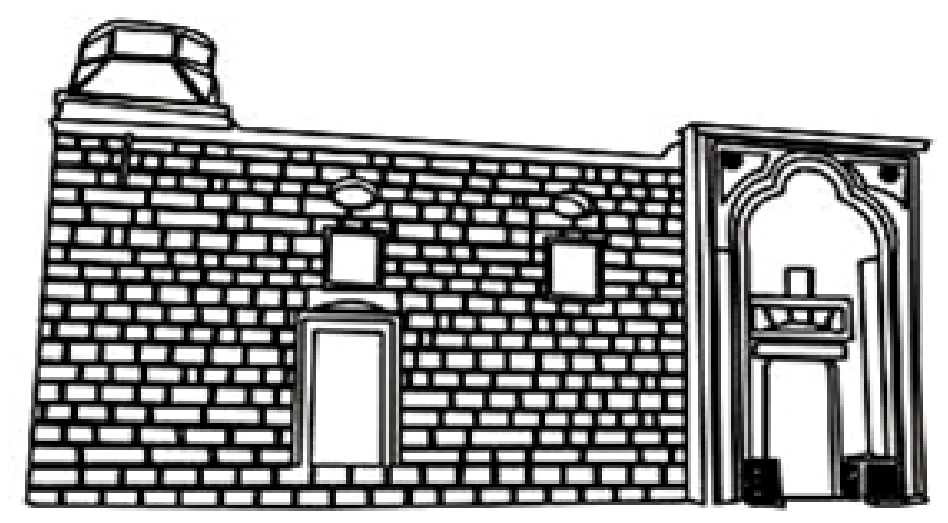

Figure 2. Plan of the façade of Helal mosque shows the main and secondary rectangular entrance.

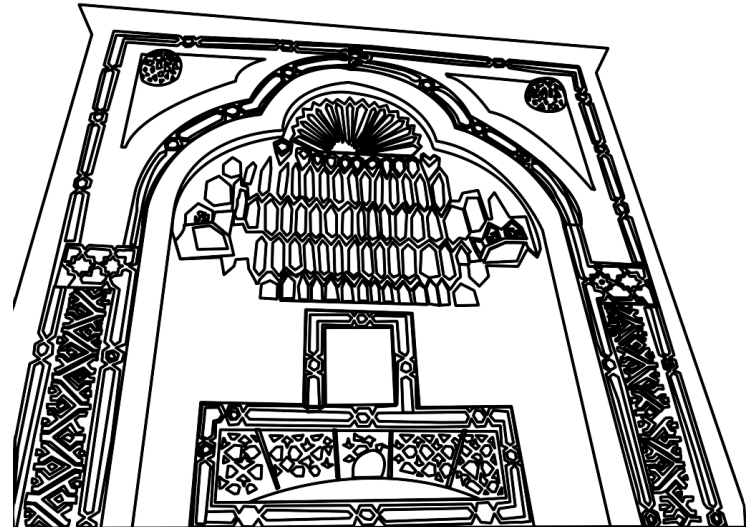

(a)

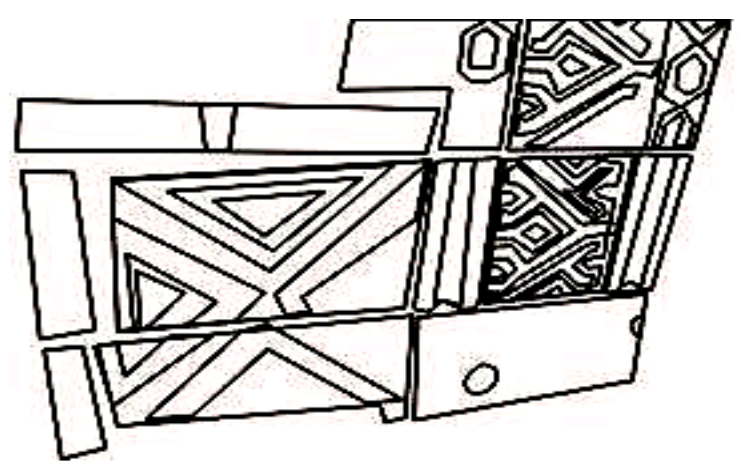

(b)

Figure 3. Architecture plan of Islamic decoration at the mosque façade. a-The high part of the tall portal shows stalactite, vousoir, threshold and Mafruk decorations; b-Islamic decoration at the low part of the façade which disappeared under the Portland cement and discovered during restoration.

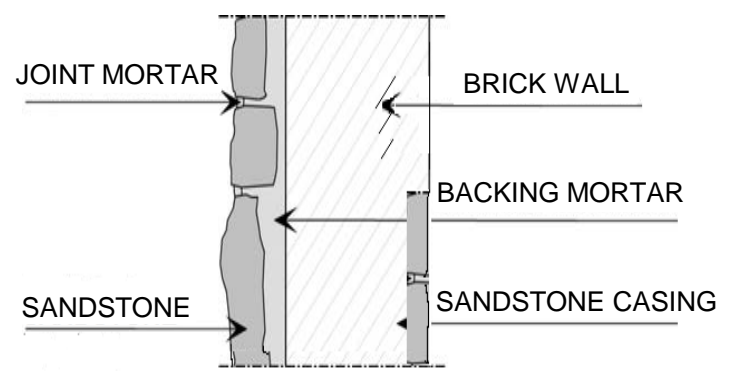

Figure 4. Bulding matrials of Helal mosque, external wall assembly consists of sandstone, joint mortar, backing mortar, eternal wall from brick wall, sandstone cladding at the low part from brick wall with height $120 \mathrm{~cm}$.

reasons that led to leakage of rainwater which lead to the internal elements of the mosque affected by chemical conversion. From the ecological point of view, some aggressive environmental features portray the study zone. High rate of moisture content everywhere throughout the year because of many reason; the old drainage system is insufficient and is the cause of water infiltration and streaming on the walls, which accelerate deterioration, there is no sanitary drainage system in the Um El-Nour village, the sewage depends on sewage, and also the main reason for the water rise is the sewage water from cultivated lands. This water rich in chloride and total dissolved solids reacts with the lower parts of walls causing several damages on the stone and bricks surface and in its pore system [1] (Figure 6). The growth of salt crystals within the pores of a stone can generate stresses that are sufficient to overcome the stone's tensile strength and turn the stone to a powder and also decrease the 


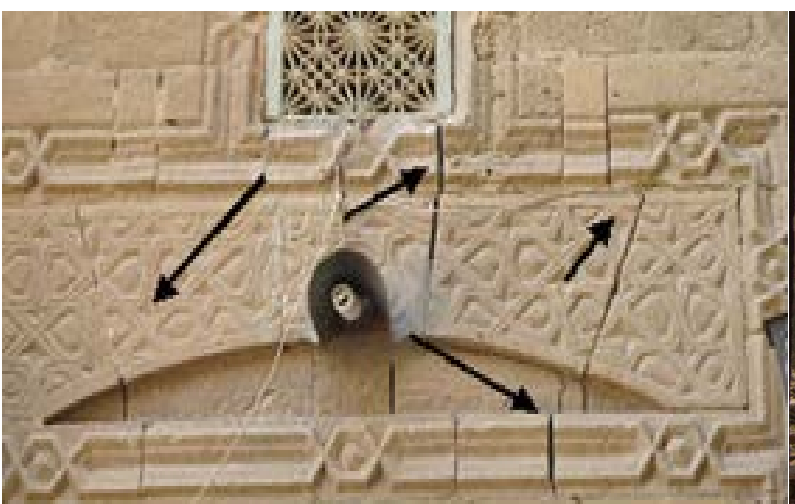

(a)

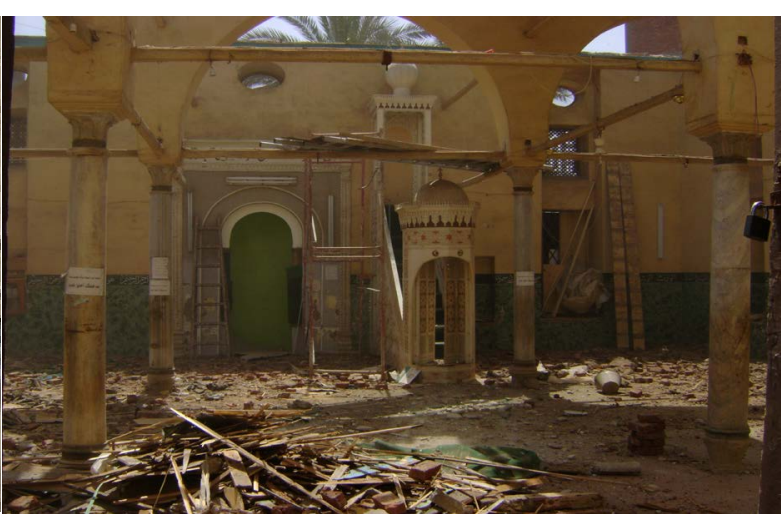

(b)

Figure 5. a-Cracks and macro cracks at the entrance of Helal mosque; b-Collapse of large parts of the ceiling of the mosque, especially north arcade.

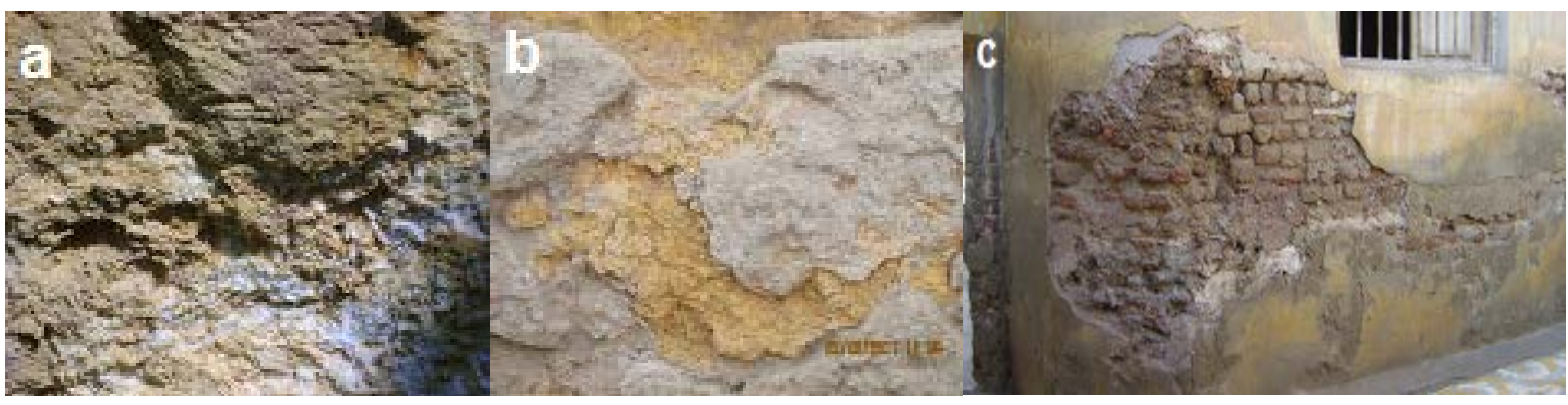

Figure 6. Photograph of decay features common at the Helal mosque. a-Efflorescence's to light-colored crust tracing the surface; b-Scars of flaking, c-Lost in brick, detachment of plaster and soiling by groundwater at the lower part of the mosque.

overall strength of the stone and bricks [2]. In addition, many brick blocks are seriously lost their internal cohesion, resistance and big numbers of these bricks become weak and some blocks were completely lost. Much more serious, however, was the impact of the development of damaging salts, which led to further total loss of the old plasterwork of the both in internal and in external walls and losing of mortar's joints which threaten the physical structure of the brick walls were observed clearly. Moreover, many areas show an extensive network of cracks associated with a spread surface and detachments, cracks in the wall allow water to penetrate into the stone and bricks increasing its moisture stress and deterioration. Additional factors that cause damage to the mosque include mishandling, worsened by writings, neglect and other vandalism action like the great number of worshippers. One of the most important reasons for degradation at Helal mosque was the old faulty restoration. The old restoration at the mosque was done by using strong Portland cement mortar and industrial lacquers, many Islamic decorations in the mosque façade disappeared (Figure 7(a)), because of these mortars and many aspects of damage as peel off the layers of stone and brick surface were noticed due to salt generated by using Portland cement. Pollutants attack Portland cement and leading to an increase in volume and consequent disruption of mortars and masonry. Concrete may erode due to the action of weather and pollutants [3]. In addition, modern lacquers, piece of carpets and industrial oily paints were used in covering the prayer niche (Mihrab) and motifs surround, this led to the disappearance of these ornaments from the viewer (Figure 7(b), Figure 7(c)), "Observations after the removal of the salt contaminated plaster and Portland cement areas revealed these decorations during restoration process”. The action of natural weathering agents and environmental pollution on the stone facade has compounded. Therefore, dirt, dust and black rust covering the façade.

\section{Materials and Methods}

The samples were chosen from various building materials at the mosque as stone, mortar and deterioration products for the purpose of determine the building material to explain the causes of damage and to carry out suitable conservation. Deferent stone and mortar samples achieved using a Zeiss, Axio Can MRC5 Stereoscopic 


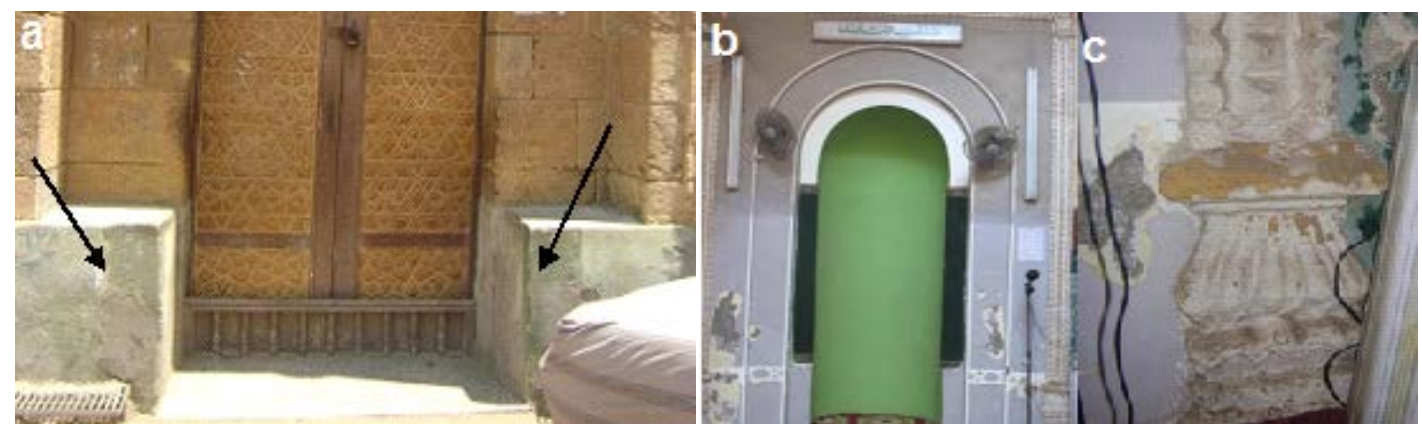

Figure 7. Old faulty restorations by Portland cement. a-Disappeared of Islamic decorations in the mosque façade by cement; b-Old restoration around mihrab which covered the decoration with Portland cement, industrial lacquers and carpet; c-The decoration was covered with lime and gypsum. Collapse of large parts of the ceiling of the mosque, especially north arcade.

microscope with Discovery V.20 camera. The minerals characteristics, texture, cement materials of building materials samples further examined by using Olympus BX51 TF Japan attached with digital camera under magnification 20x up to 40x. A Scanning electron microscopy (SEM) used to observe the rock forming minerals, weathered minerals, details of morphological features of the surface particles, voids and its weathering status. The SEM was a JEOL JSM 6400 coupled with an energy dispersive X-ray spectrometer (EDS) was used to determine the chemical composition of the building materials. Mineral compositions of the samples inducted by X-ray diffraction patterns, using a Philips X-ray PW 1840 diffractometer. The patterns were run with Ni-filtered, $\mathrm{Cu} \mathrm{K} \alpha$ radiation $(\lambda=1.54056 \AA)$ at $30 \mathrm{kV}$ and $10 \mathrm{~mA}$, and scan speed of $2^{\circ}(2 \theta) / \mathrm{min}$.

\section{Materials Characterization}

\subsection{Stone Sample}

Light optical microscope reveals that, the samples suffer from several deterioration of its structural coherence, the photograph shows cavities, cracks and macro cracks disintegration, chosen of quartz grains, fossils and iron concentration. In addition, LOM photographs reveal that affected chemical process produced micro-fractures and cleavages dissecting the quartz grains into several sub-individual grains as it shown in Figure 8. Petrographic study using polarized light (PL) and crossed nicols (XN) prism confirmed that the stone used in the facade of the mosque consists of such rock-forming minerals as quartz, rock fragments, dolomite, plagioclase and microcline (Figure 9). Quartz crystals are angular to subrounded in shape and fine to medium grained. Quartz grains occur as turbid color, they are surrounded by feldspars (partially altered to Sericite) with cement of dolomite and iron oxides. Dolomite crystal appears as transparent to translucent in appearance and the crystal habit include saddle-shaped rhombohedral twins. Due to the high concentration of quartz and high amounts of dolomite and feldspars and other lithic fragments, the sandstone can be classified in petrological terms as dolomitic sandstone. X-ray diffraction (Figure 10) results identified quartz $\left(\mathrm{SiO}_{2}\right)$, dolomite (Ca, $\left.\mathrm{Mg} \mathrm{CO}_{3}\right)$, albite (NaAl$\left.\mathrm{Si}_{3} \mathrm{O}_{8}\right)$, hematite $\left(\mathrm{Fe}_{2} \mathrm{O}_{3}\right)$ and halite $(\mathrm{NaCl})$ and they were marked with high peak. According these studies, it can claimed that, the stone in the façade consisted of Quartz as a major minerals and high ratio of dolomite (Dolomitic sandstone). The results of salt sample found at the surface of the stone indicate that a highly weathering occurred on the sandstone by halite salts that observed clearly by SEM. Mineralogical investigated of the mortar between stone blocks in the Helal mosque façade confirmed that, it consists mainly of calcite and gypsum as major, quartz as a minor, hematite and augite as traces. It can claim that, the stone mortar consists of mixture of gypsum, lime and a little amount of sand. EDX microanalysis of the stone sample (Figure 11) showed that Si, $\mathrm{Mg}, \mathrm{Fe}, \mathrm{Ti}, \mathrm{Sr}, \mathrm{Cl}$ and Na. Considering this results, it can be claimed that, the stone samples consists of quartz, dolomite, feldspars and heavy metals ( $\mathrm{Fe}, \mathrm{Ti}$ and $\mathrm{Sr}$ ) generally increase in the outermost surfaces of the black crusts relative to the sample interiors. This attributed to polluted gases derived mainly from diesel engine exhaust, which is primarily composed of soot and metallic particles bearing $\mathrm{Fe}$ and $\mathrm{Fe}-\mathrm{S}$ as major elements, Ti, and $\mathrm{Sr}$ as trace elements. These elements play a major role in the catalytic oxidation rates of $\mathrm{SO}_{2}$ [4]. The SEM examination micrographs (Figure 12) of some degraded stone samples from the façade of Helal mosque revealed, the sample consists mainly of quartz grains cemented with dolomite and iron. It also showed the major 


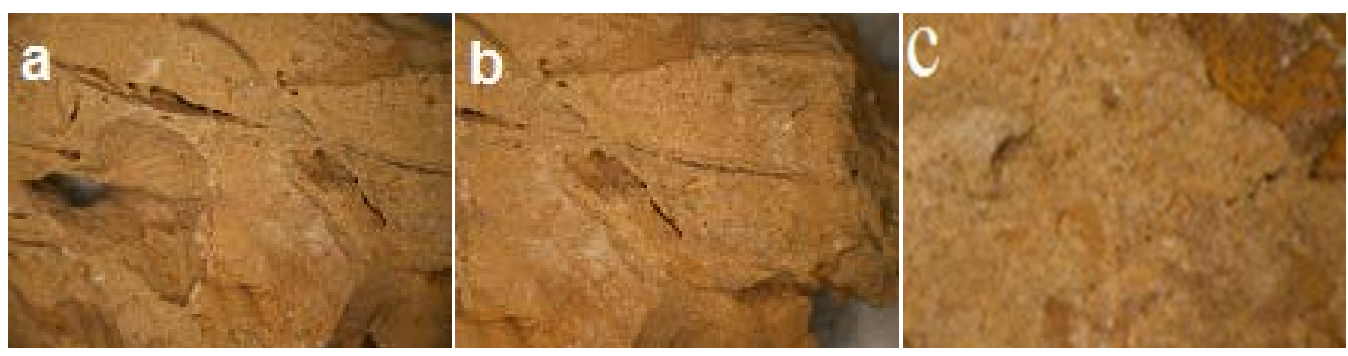

Figure 8. LOM microscopically image of the surface of sandstone samples shows, cavities, cracks and macroceracks, fossils and iron concentration.
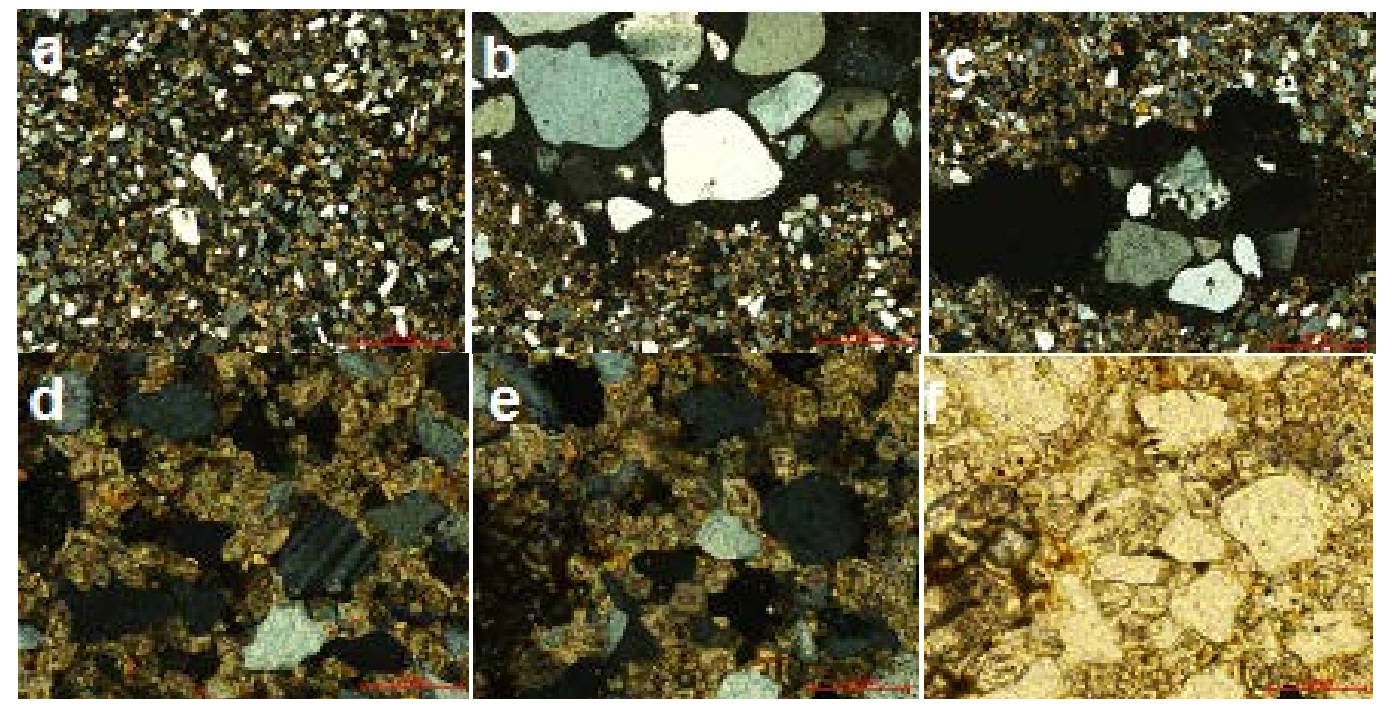

Figure 9. Mineralogical characteristics of the sandstone in the façade of Helal mosque. a-Minerals content of sandstone samples; b-Subrounded grains of calcite; c-Turbid color of quartz grains by clay minerals; d, e-Crystal of dolomite between quartz grains; $\mathrm{f}-$ Rhombohedral twins of dolomite grains.

deterioration cause for the samples is abundance of soluble salts. Sodium chloride was existing between mineral constituents of stone and destroyed their mineral constituents. It also showed weathering phenomena such as pitting, voids, cracking and micro-exfoliation at grain boundaries. In addition dissolution of cements occurs of the sandstone leads to an increasing in porosity, disintegration and loss of cohesion of the stone causing the sandstone became preamble and leads to decrease of strength qualities. SEM observations showed extensive penetration of heterotrophic micro flora, composed of algae and fungi. This type of biological growth provides a wet environment for chemical and biological interaction which increases the rate of weathering [1]. SEM investigation of the mortar samples showed the collapse of internal structure, voids, loose of binding material and $\mathrm{NaCl}$ salts crystallization between mineral grains (Figure 12).

\subsection{The Brick Samples}

Examination by light optical microscope (LOM) confirmed a lot of deterioration features at the brick samples, the photograph shows cavities, cracks and macro crack as a result of crystallization and pressure salts. In addition, the examination showed thread of lime mortar overlap the outer surface of a brick surface with gaps, with the presence of grains of sand, graduated from the size of the average flour (Figure 13). Petrographic study of bricks (Figure 14) shows the heterogeneity of the archaeological brick components by the existence of precise and coherent fabric of granules, color gradient inside the samples as a result of the conditions of burning was observed and small proportions of calcite (lime) which serves to control the temperature and works to connect granules bricks earned cohesion was found. This study indicated the brick consists mainly of quartz, iron oxides and clay minerals. Furthermore some burning fibers were observed, which were added during brick making process. X-ray diffraction (Figure 15(a)) indicated that the brick consists mainly of quartz $\left(\mathrm{SiO}_{2}\right)$, Albite 

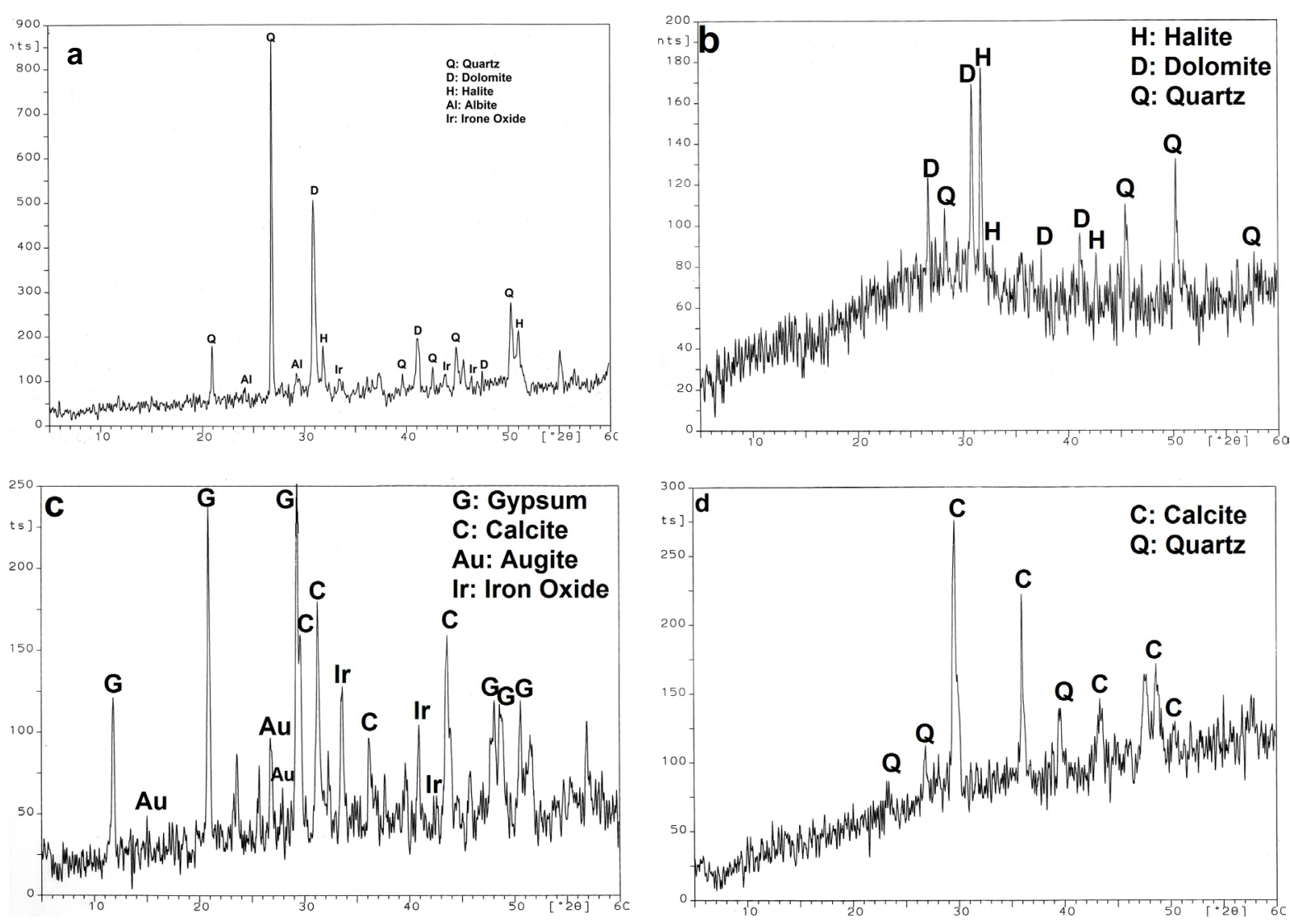

Figure 10. XRD pattern of building materials of Helal mosque. a-Sandstone samples; b-Salt samples; c, d-Mortar samples.

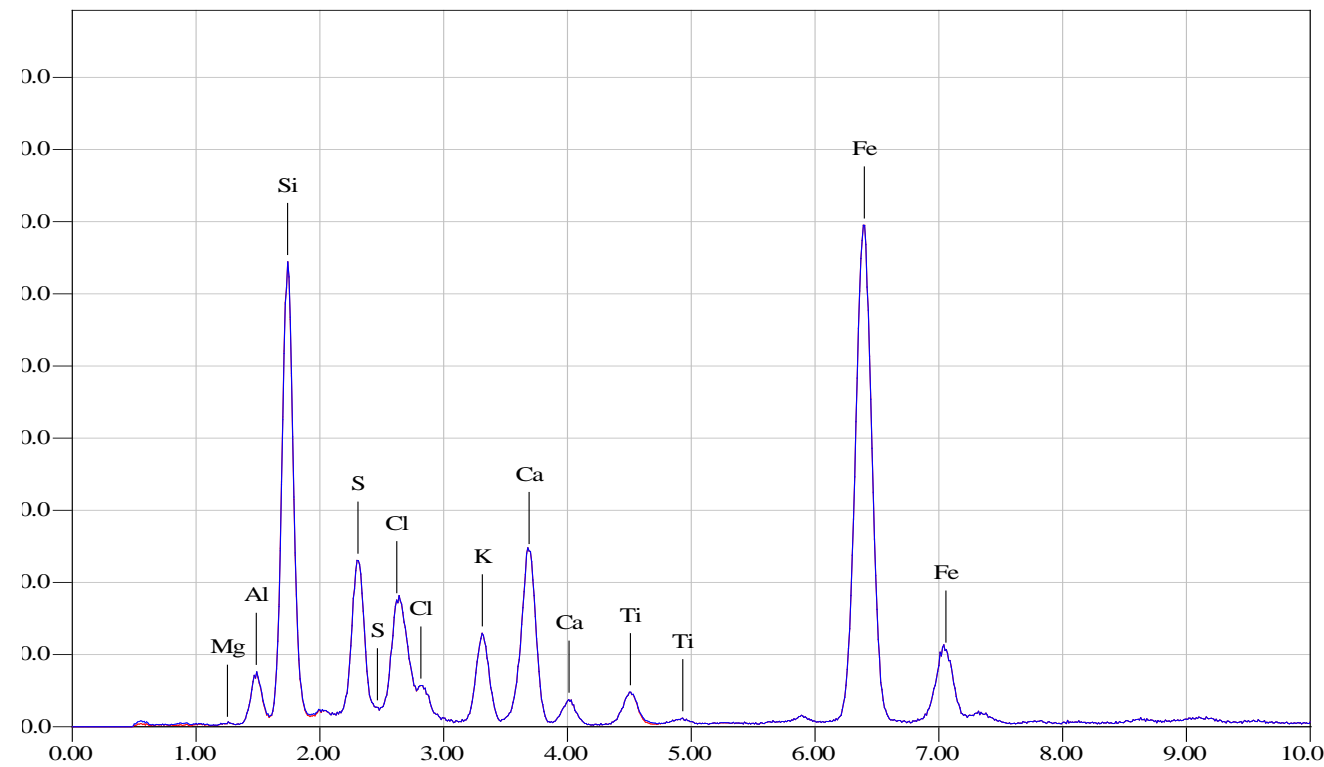

Figure 11. EDX pattern of sandstone sample.

$\left(\mathrm{NaAlSi}_{3} \mathrm{O}_{8}\right)$, calcite $\left(\mathrm{CaCO}_{3}\right)$, in addition to halite $(\mathrm{NaCl})$, iron oxide and clay minerals. Furthermore, the analysis of brick mortar (Figure 15(b)) shows that the sample consists mainly of calcite, quartz, albite, iron oxide and halite. On other hand, XRD analysis of plaster layers of the interior walls of the Helal mosque shows that it 


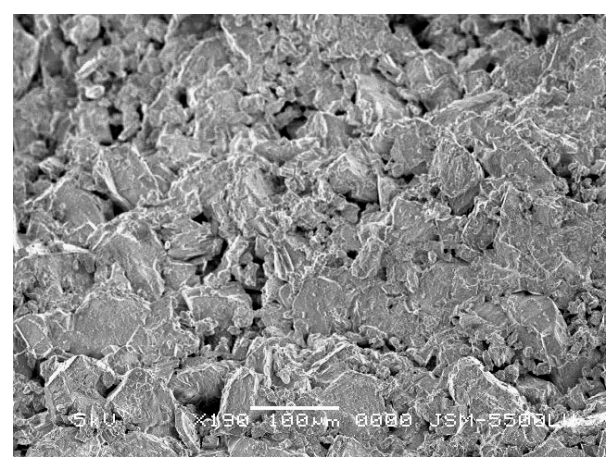

(a)

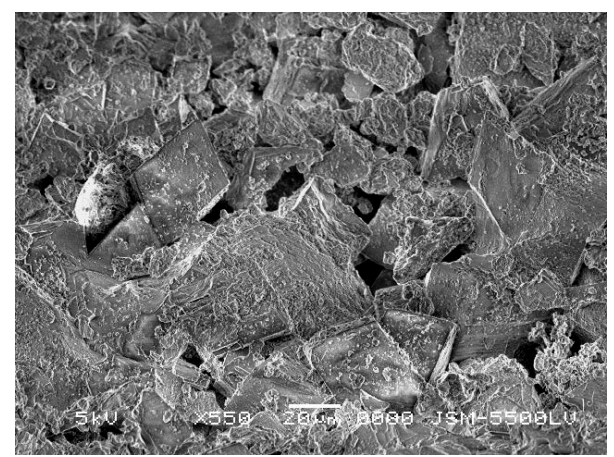

(c)

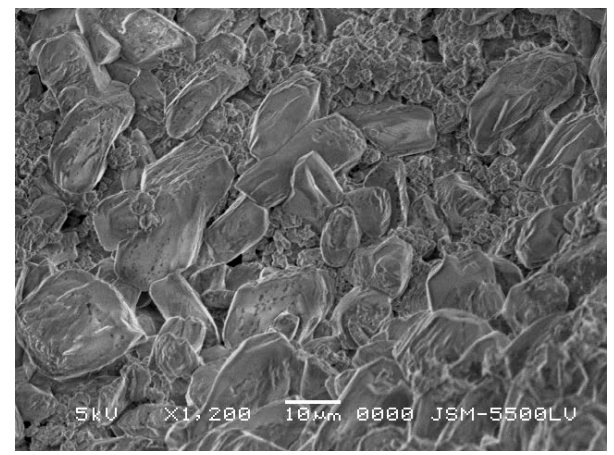

(e)

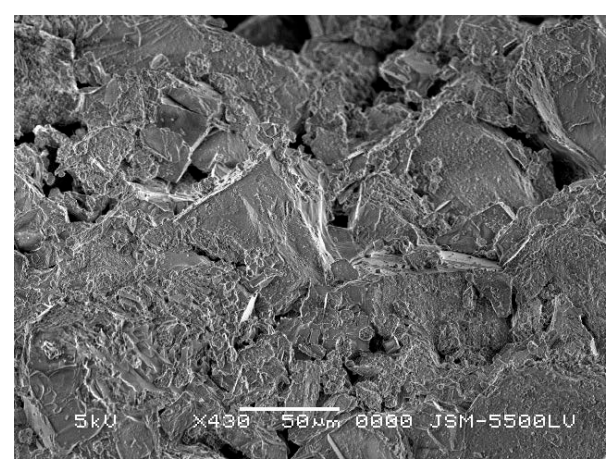

(b)

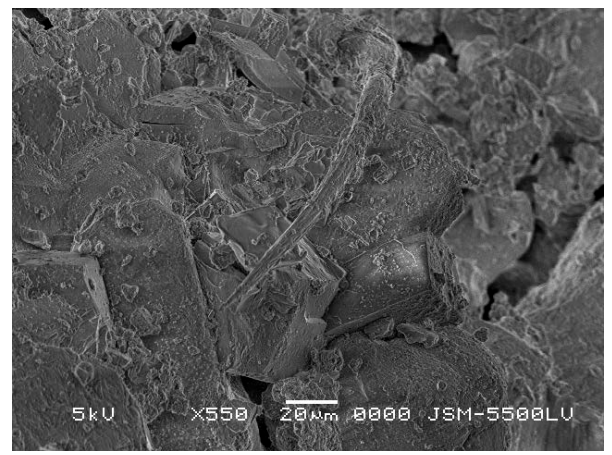

(d)

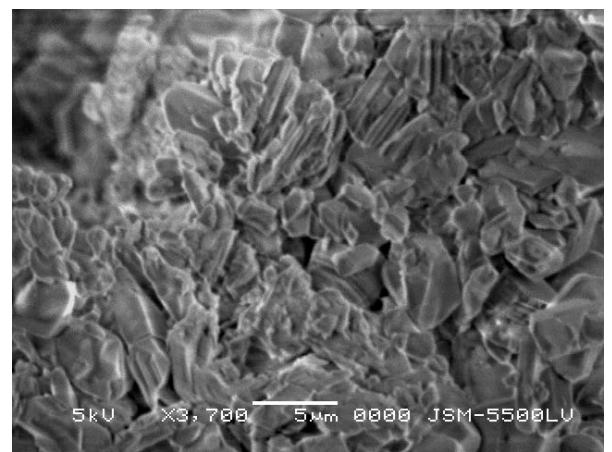

(f)

Figure 12. Electro-micrograph of investigated sandstone samples by SEM. a, b, c-Disintegration and loss of cohesion of the sandstone; d-Extensive penetration of heterotrophic micro flora; e, $\mathrm{f}$-Collapse of internal structure of mortae between sandstone blocks.
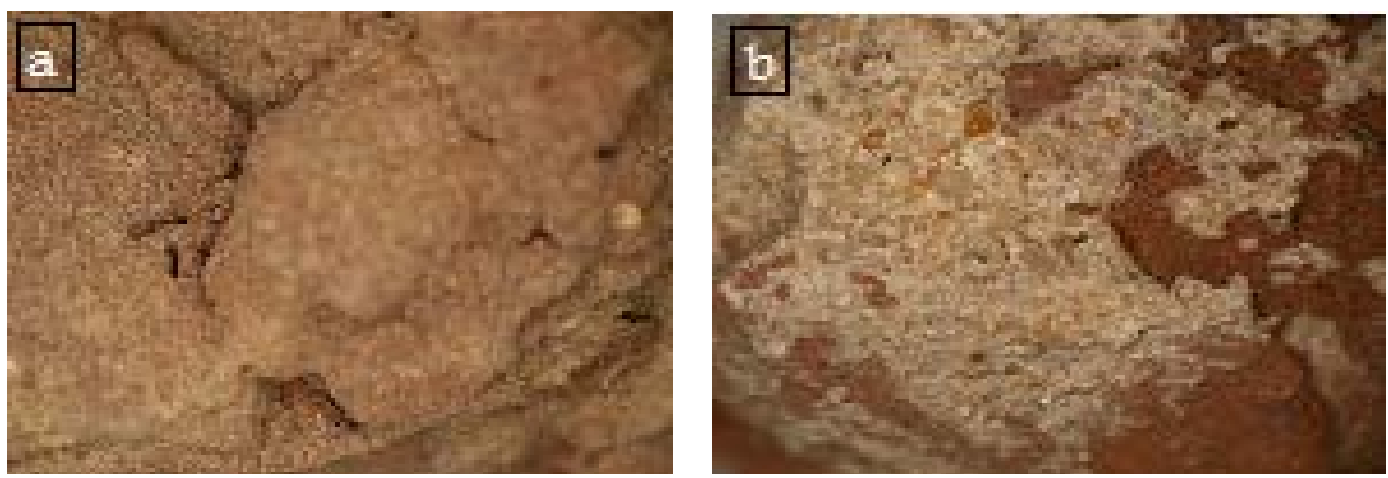

Figure 13. Micrograph of investigated brick samples by LOM. 

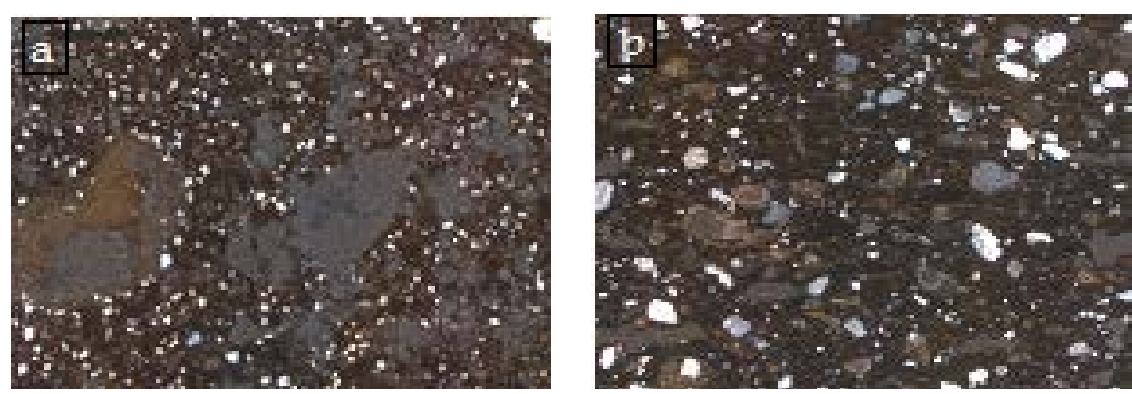

Figure 14. Mineralogical characteristics of the brick in Helal mosque.

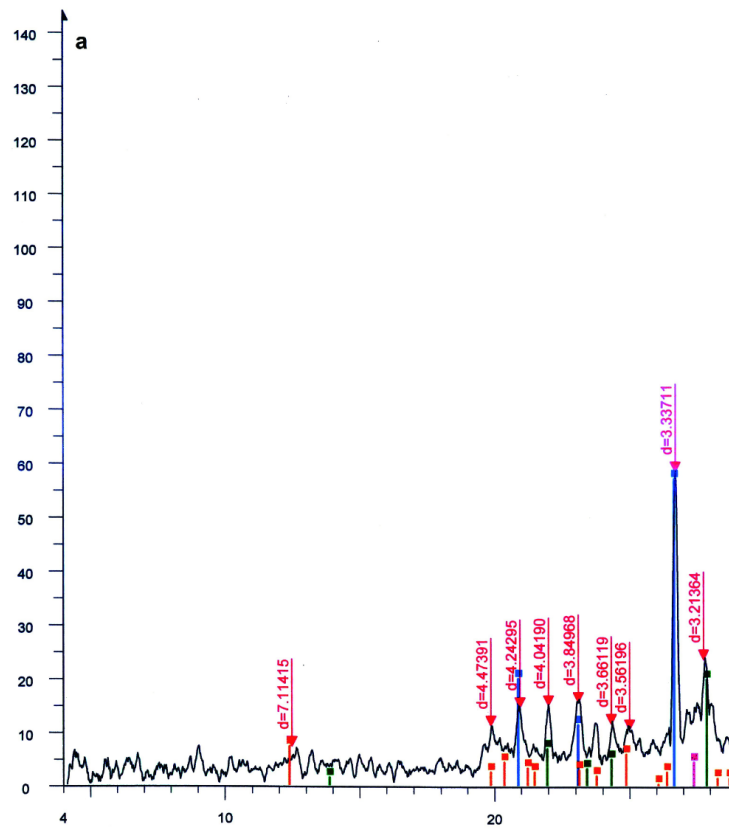

01-0739 (D) - Albite - NaAISi3OB

88-1808 (C) - Calcite - $\mathrm{Ca}(\mathrm{CO})$

75-0306 (C) - Halite - NaCl

14-0164 (D) - Kaolinite-1A - Al2Si2O5

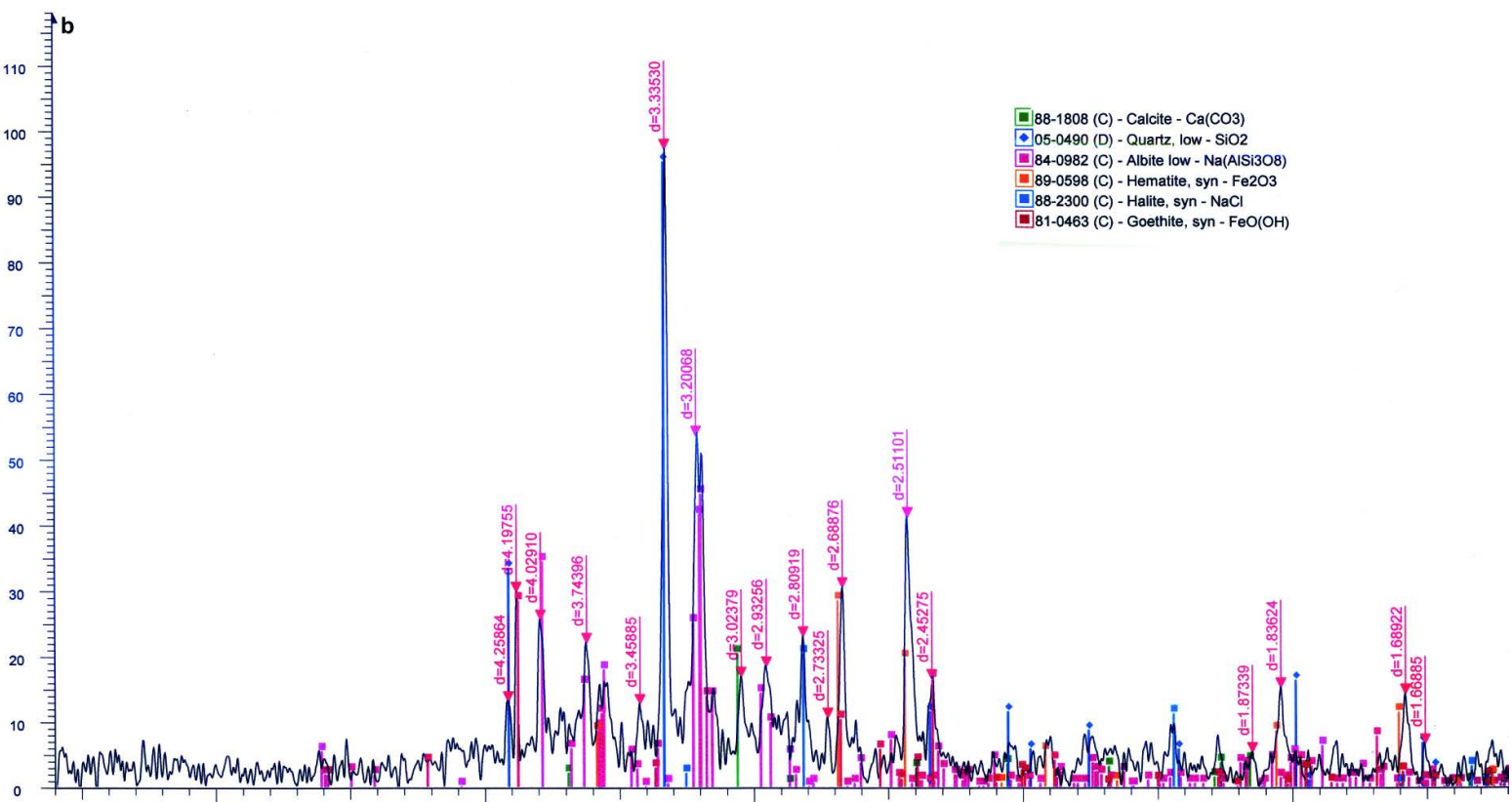

Figure 15. XRD pattern of brick and mortar brick samples. a-Brick sample, b-Mortar brick sample. 
consists of calcite and quartz.EDX microanalysis of brick sample (Figure 16(a)) showed that Si, Ca, Fe were the major elements in the sample. Considerable amounts of $\mathrm{Al}, \mathrm{Mg}, \mathrm{K}$ and $\mathrm{Cl}$ were also recorded. The EDX analysis confirmed the brick mortar consists of $\mathrm{Ca}, \mathrm{Si}$, as a major elements and small amount of $\mathrm{Fe}, \mathrm{Mg}$ and $\mathrm{Na}$ (Figure 16(b)). Considering the EDX results, it can be concluded that, the brick consists of quartz, feldspar, calcite, iron oxide and halite as salts. Furthermore, the brick mortar is lime mortar that contains of calcite, quartz and halite. These results confirmed the XRD results. SEM microscope observation of brick (Figures 17(a)-(d)) shows that, there are some cracks, gaps and voids which led to the disintegration, separation, thus erosion and weakness of the brick internal structure. Also, dissolving of some brick components and crystallizing some types of salts were detected. SEM study also indicated growth of hyphae of fungi and remains of alga inside the brick. Furthermore some fibers were observed, which were added during brick making process. Results of the scanning electron microscope investigations showed that the surface of brick mortar was fragmented and damaged, the surface that contains halite crystals, sand and lime (Figures 17(e)-(f)).

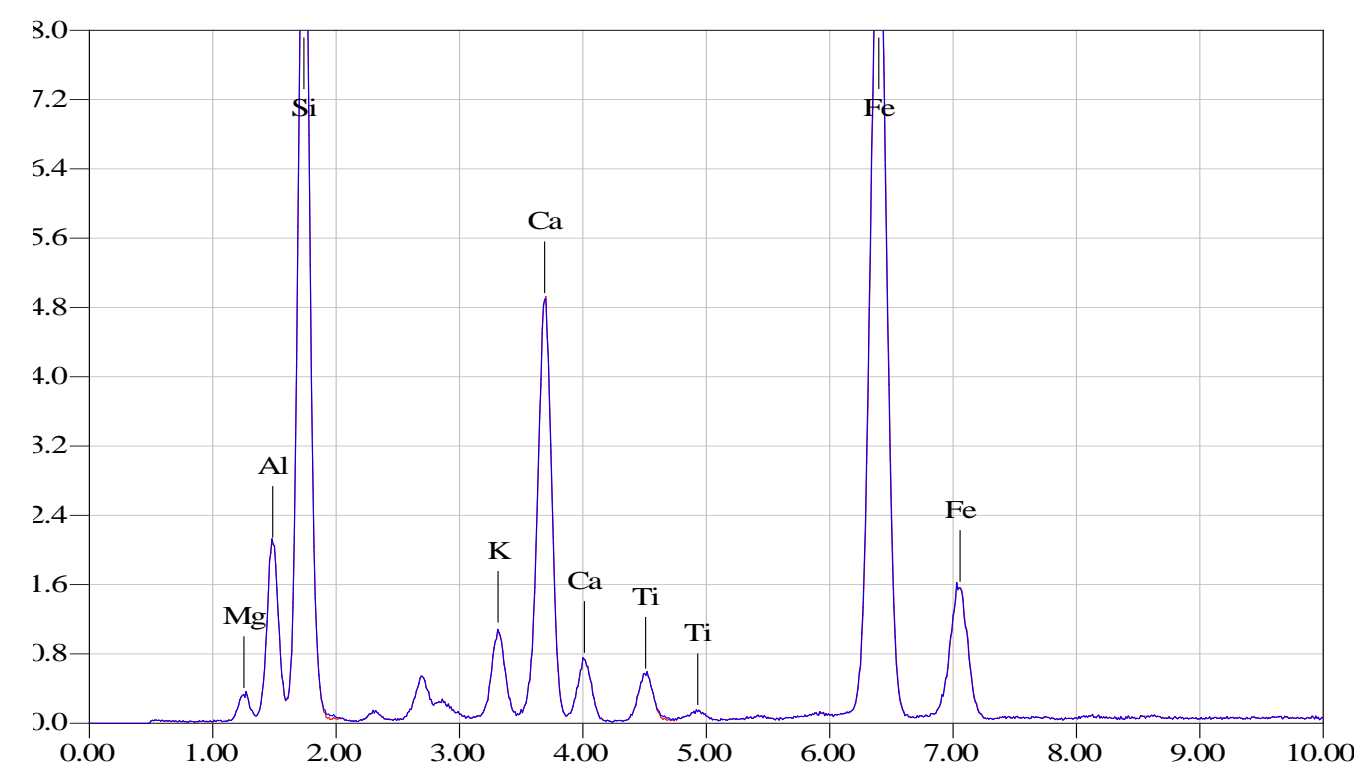

(a)

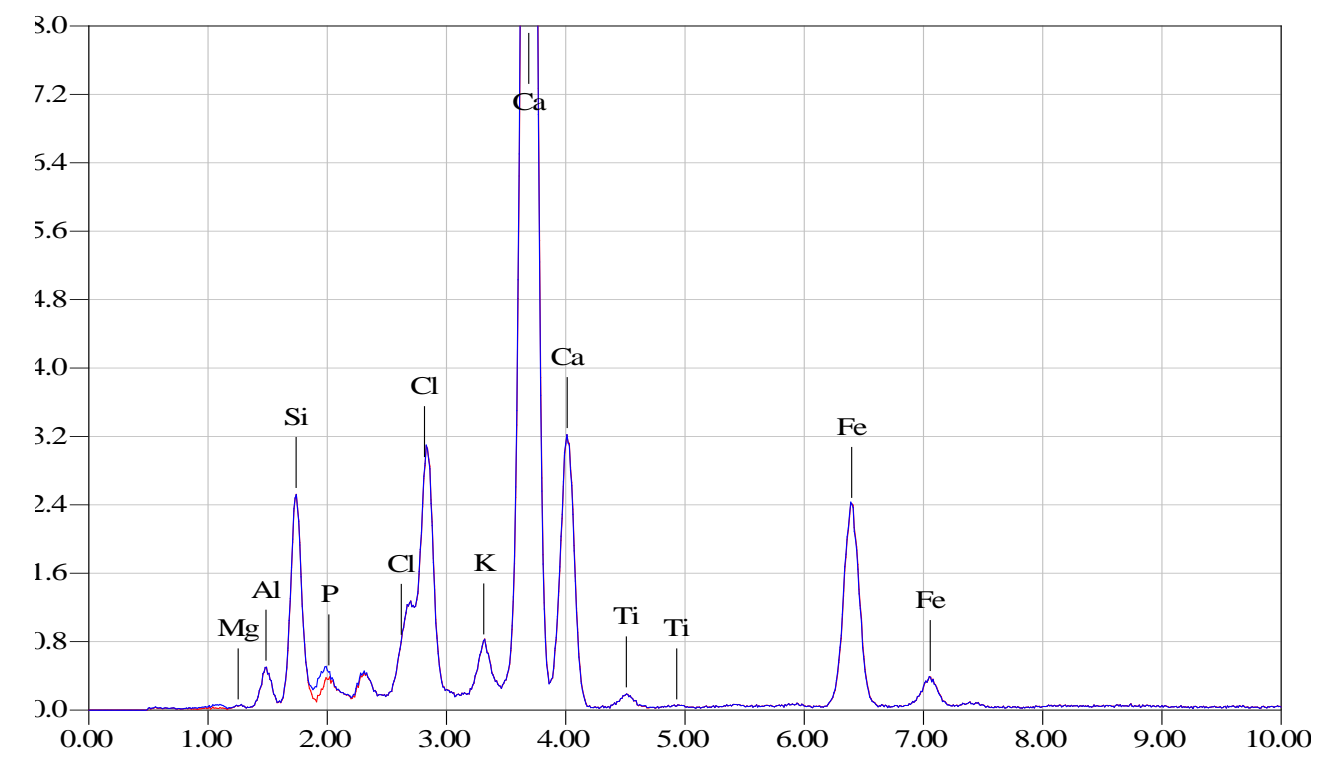

(b)

Figure 16. EDX pattern of brick and mortar brick. a—Brick samples; b-Mortar samples. 


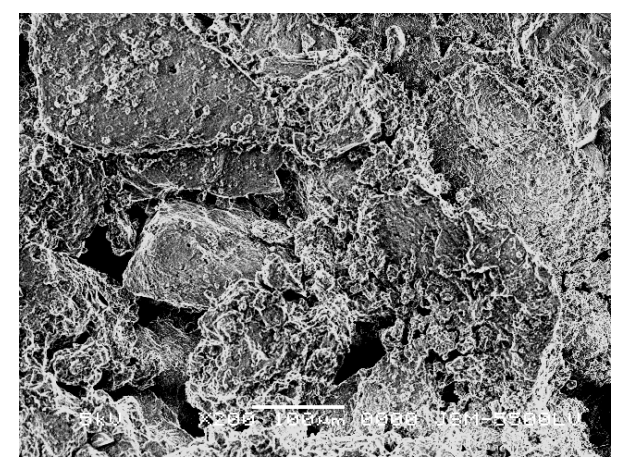

(a)

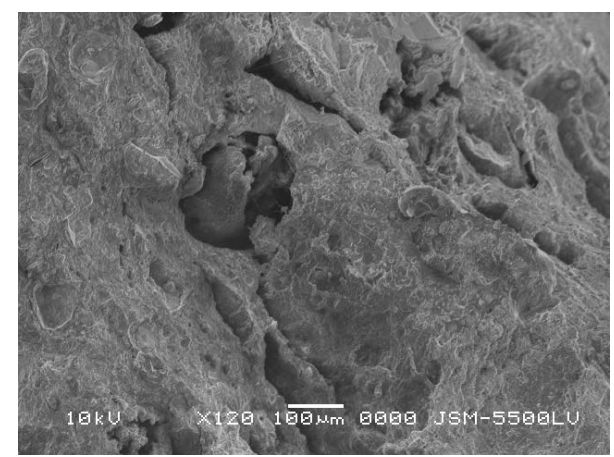

(c)

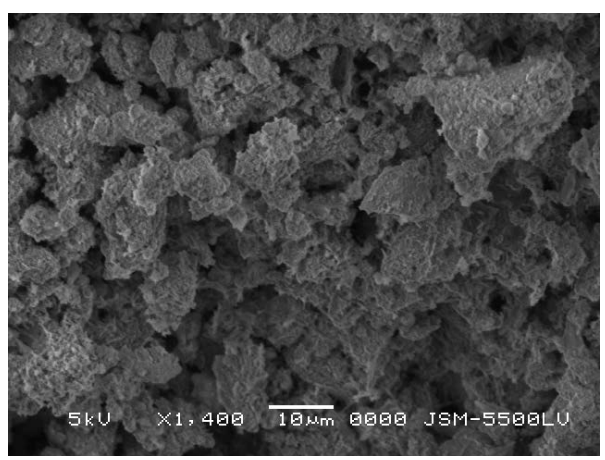

(e)

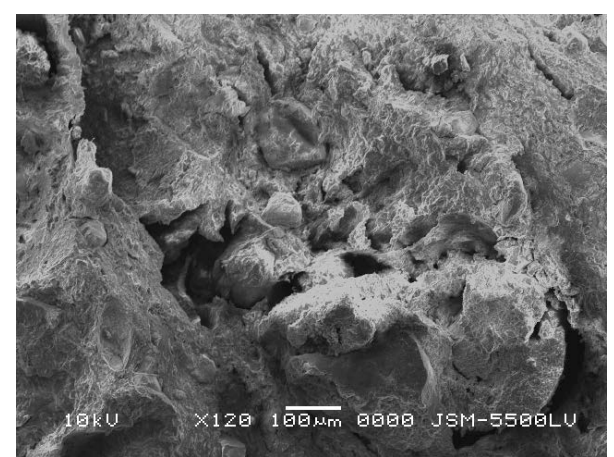

(b)

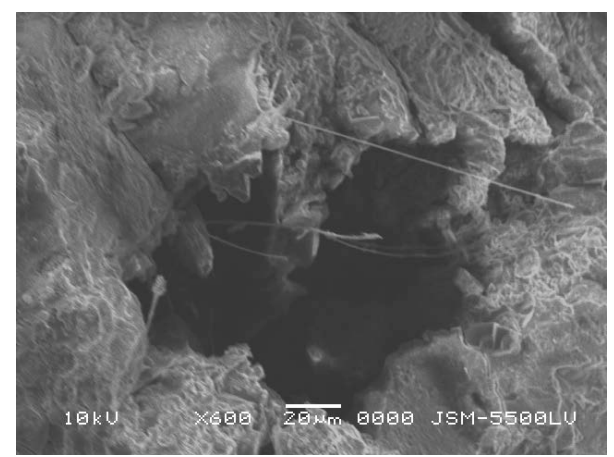

(d)

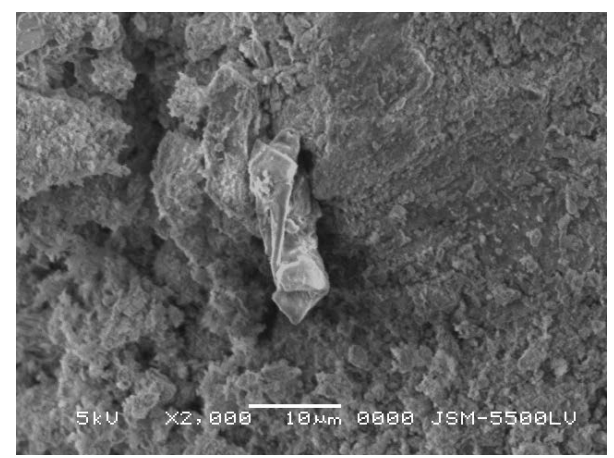

(f)

Figure 17. Electro-micrograph of investigated samples by SEM. a, b, c-Dissolution of cements and loss of cohesion between grains, gaps and voids; $d$-Remains of alge inside brick sample; e, f-Electro-micrograph of investigated mortar samples by SEM.

\section{The Applied Work (Treatment)}

The main goal of treatment was toeliminate the source of deterioration as much as possible, to restore the badly damaged appearance of the monuments, to improve its durability, and most important, to enable regular maintenance in the outdoor environment [5].

\subsection{Stages of Preparation to Work}

As a result of the above-mentioned observation and of the visual examination of the building materials, the accompanying recommendations were given for conservation treatments to be carried out:

- The state of the building materials was recorded before any intercession. Documentation of the archeological and building components of the mosque has been done. No previous studies on the mosque from the archaeological or conservation state.

- Overview of the cracks and distortion of structure were completed. The movement of cracks has been 
studied by fixing dabs of plaster to the basic masonry.

- Due to the tricky condition of protection it is important to intervene urgently.

- All materials used, have been extensively tested andused in the conservation field for more years.

- It is fundamental to repair the ceiling of the mosque, to control the water infiltration and presumably enhance the rainwater drainage system.We can summarize the restoration of themosque in the following.

\subsection{Roof Restoration}

It the first interventions were done on architecture structure in order to stabilize the conservation state of the mosque. Restoration procedure ought to be completed contemporaneously with the roof repair, utilizing a roof repairing, using a roof protection which will guarantee perfect insulation from rain water on all areas to be treated during the project. This is an essential condition when carrying out conservation treatments. The roof were repaired by suitable new wood panels as the same way as with the old panels. The new and old wooden panels had been sterilized using Thymol as a fungicide and an insecticide. The floor of the ceiling insulate against moisture by covering with Cerotekt 1 material (Bituminous emulsion using as roof insulation against moisture and water, producing by $\mathrm{CMB}$ ) and then plastic layer were put above Certekt 1 , above that, the coil burlap soaked in asphalt were covered in order to stop the water infiltration (Figure 18).

\subsection{Cleaning and Removing the Faulty Old Restoration}

-Removal of Portland cement mortar and industrial lacquers were done with mechanical cleaning as chisel and stiff bristle. Some parts of the Islamic decorations had disappeared completely because of the new fault restoration with cement mortar, these decorations were revealed step by step by mechanical cleaning, in addition, compressed air and abrasive were used to remove all loose scale, loose mortar, superficial salts that might remain on the surface and remove harmful or undesirable deposits. Dust and debris were removed with a brush and a vacuum cleaner. We finish the work by flushing with water alone. After that we deep tamp all open joints with lime mortar (Figure 19).

Salt extraction

-Cleaning and salts extraction was done by mechanical methods for reducing the crystallized salts by scalpel to remove thicker layers of salts. Sepiolite poultice with distilled water was applied to the stone surface to draw out the halite salts.

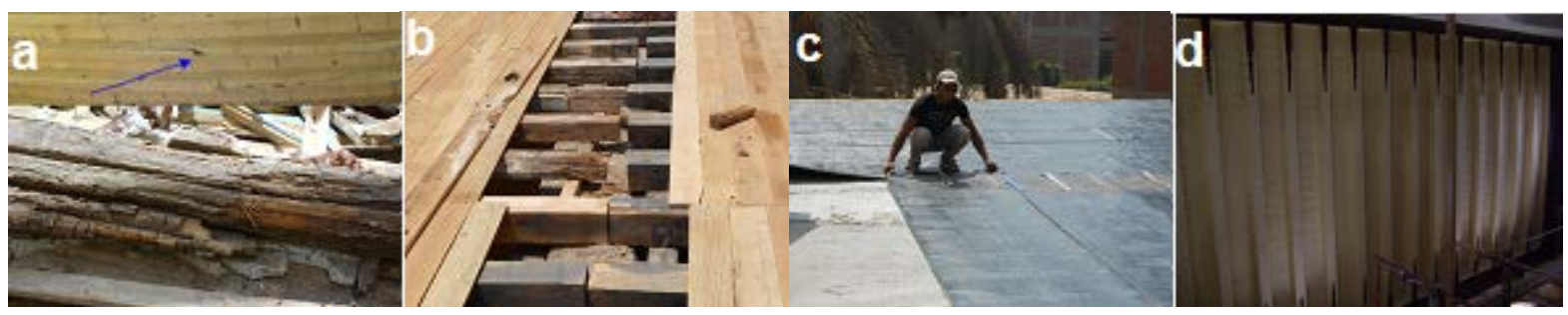

Figure 18. Restoration steps of the ceiling of Helal mosque. a-Deteriorated ceiling wood; b-New wooden panels during restoration process; c-Certekt layer; $\mathrm{d}$ - -The ceiling after repaired.
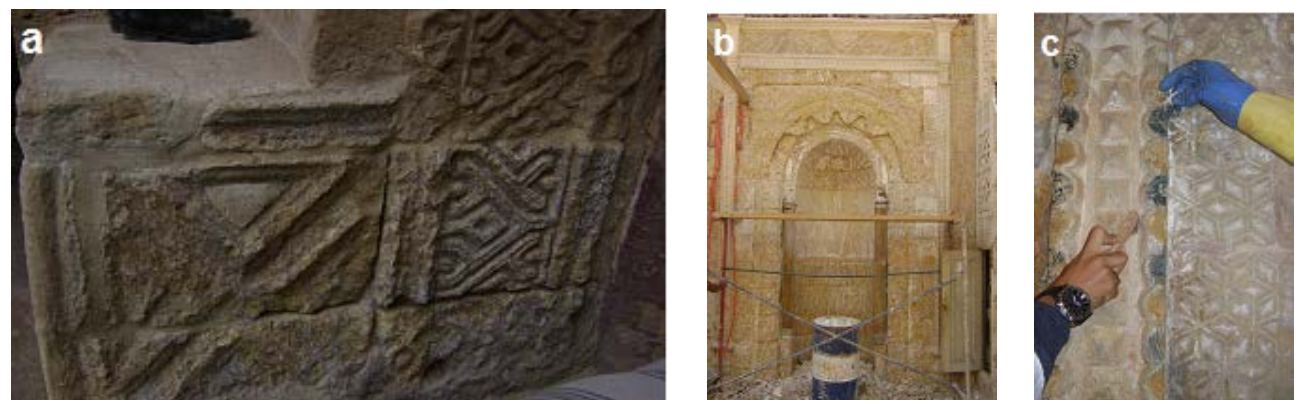

Figure 19. a, b, c-Removing the old restoration with Portland cement and lacquers and revealed the Islamic decoration by mechanical cleaning. 


\subsection{Completion the Missing Parts of Decoration Elements}

During removing the Portland cement mortar and industrial lacquers, we found beautiful Islamic decorations at the entrance of Helal mosque and around the prayer niche, but it was in a bad condition, because of the several decays, some of parts of these elements were lost and deteriorated, so:

-Pre-consolidation was carried out on separate stone peels which are in danger of collapsing, using Japanese tissue paper and a solution of $10 \%$ of primal AC33.

-Split, detached and broken pieces were reattaching by 50\% Primal AC33 in water with the aid of a piece of cotton with the syringe.

-When it was necessary to provide support for surfaces, impregnation with Ethyl silicate with a sprayed with hand sprayers was carried out on very disaggregated areas of decoration to restore some strength because of its ability to penetrate the stone, resulting from it's a low viscosity and a low contact angle of, its ability to link between the grains of mineral constituents of the stones and the surface of the stone become water-repellent [6]. The Ethyl silicate applied to the surface with paying attention to avoid any overflow.

-The missing parts of the decoration were restored by reproduction. Reproduction entails copying an extant artefact, often in order to replace some missing or decayed parts, generally decorative, to maintain its aesthetic harmony [7]. Then, reproduction of the lost decoration was carried out. Through evaluating various techniques of completion the missing parts of sandstone by reproduction process, lime mortar consists of lime, sand, white cement (2:1:1/2) mixed with 15\% Edibond in water (Basic of Latex Botadin Stearin and production of CMB) reported previously by several authors [8]. In addition lime mortar similar to the old preparation layer. The completed the missing parts of the ornaments were carried out directly by engraving methods. The mortar was applied with a spatula at the missing parts until it comes well to the edges of the ornament film, we transferred the missing parts of the decorations from full counterparts and printed the outlines at the mortar surface, after that, the missing parts of the ornaments were carried out directly by engraving methods. After finishing, iron oxide was used to approximate its color to the patina at the original parts (Figure 20).

-Replacement and completion the missing and deteriorated stone blocks were carried out to compensate, anchor the loss of the deteriorated stone on the mosque façade with the original materials; similar dolomitic sandstone blocks and lime mortar consisting of 2 sand +1 lime $+1 / 2$ white cement $+10 \%$ Ediopond in water. We tried to use the original stone for repair because it had the same appearance and nature and doesn $t$ damage the original stone physically, mechanically or chemically [7]. The stone blocks which used for be replacing were dressed to the original profile and designed to match the original.

-Lime-based mortar was used for filling of cracks. Insertions of Pins of stainless steel anchored with an epoxy resin in those parts which are in danger of collapsing were carried out and completion the missing parts. The mortar was applied with a spatula to flatten the putty and smooth it out until it comes well to the edges of the archaeological stone surface. After finishing, iron oxide was used to approximate its color to the patina of the original parts (Figure 21). Some of decayed sandstone blocks in the lower part of the façade were consolidated by thin coating of lime and fine aggregates rubbed firmly into the surface of the stone. The coating was intended to protect the stone.

\subsection{Re-Cladding the Lower Part of the Brick Walls by Slabs of Sandstone}

During removing the Portland cement mortar from the interior brick wall in Helal mosque, we discovered pieces
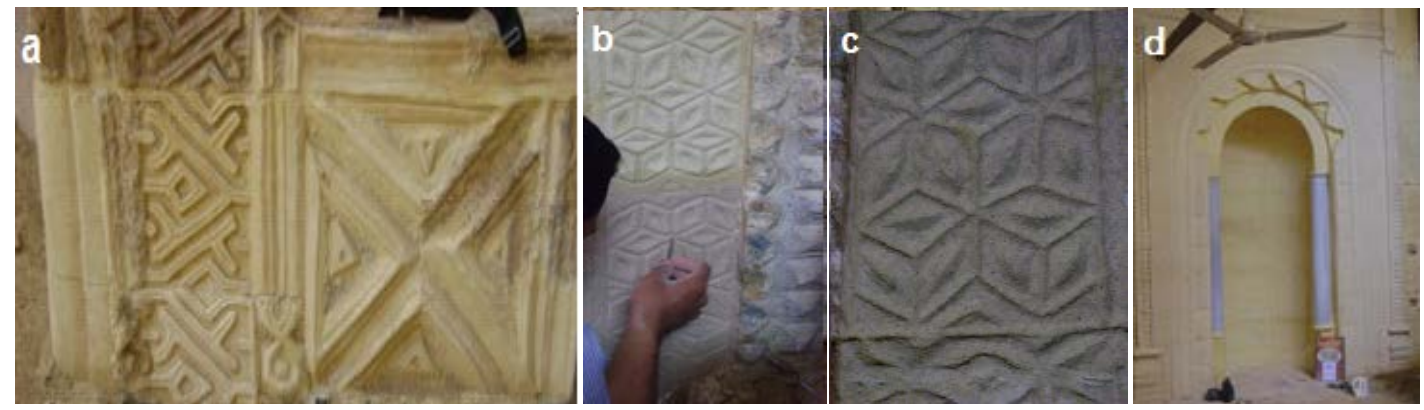

Figure 20. Completing the missing parts of decoration at the entrance of Helal mosque and around Mehrab by reproduction process and engraving methods. 

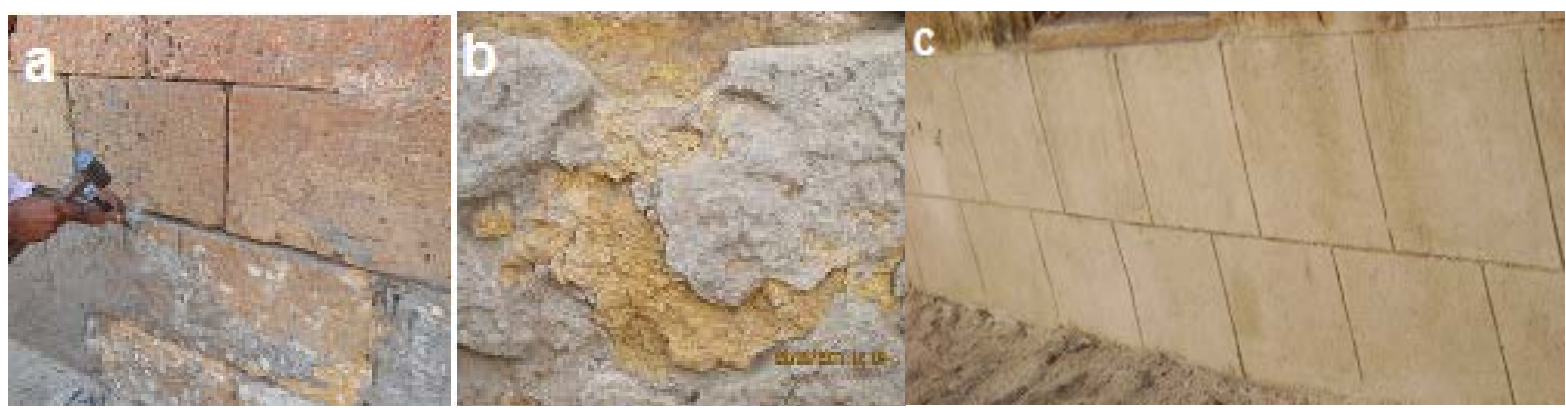

Figure 21. Completing the missing parts of decoration at the entrance of Helal mosque and around Mehrab by reproduction process and engraving methods.

of sandstone tiles covered the lower part of brick walls, the end of these tiles at $1.5 \mathrm{~m}$ from low the walls, so, we have become convinced unsubstantiated, that the lower part of the interior brick walls of the mosque was covered with sandstone slabs as cladding at $1.5 \mathrm{~m}$ height. So we decided to return this coating to the walls as a kind of protection and strengthening. First, we completed removing the Portland cement mortar, then fine grains of salts, dust and debris were removed with a brush and a vacuum cleaner, the brick and old mortars were consolidated by Ethyl Silicate. Sandstone tiles were cut at $30 \times 40 \mathrm{~cm}$ in size (this size was chosen as approximate ratios close to parts of the tiles that was discovered), these tiles has been installed on the walls using a mortar of lime and white cement as shown in (Figure 22).

\subsection{The Restoration Intervention in Brick Walls}

-For the interior brick walls, the cement mortar was removed and cleaned by mechanical methods.

- Deteriorated mortar and dust in brick joints were cleaned mechanically with a spatula and different kinds of brushes to avoid failure of adhesion of the new mortar.

-Cleaning and extraction of salts were carried out by mechanical cleaning and washing several times with water.

- After drying, the consolidation of weak, corroded parts and separate mineral grains were carried out using migrated Ethyl Silicate to increase the mechanical durability of the brick units.

- All units of bricks were protected by Eucosil (water-based sodium silicate solution made by Swiss Chem. Com) which used as a protective coating and helping protect it from water seepage with salts and densifying the material to help increase its longevity and durability.

- The completion of the missing parts of red brick were carried out by using old bricks found in the site as they may have the same mechanical and physical properties. After that, the brick walls became ready to apply thin coating of mortar lime consists of 1 lime, 2 rough sand, $1 / 2$ white cement, to cut off the source of ground water from the walls.

- The excess of the rough sand ratio and use of ordinary lime were used to form a tenuous and porous plaster which helps to abstract soluble salt without affecting the historic brick [9]. Lime plaster layers were carried out as shown in (Figure 23).

\section{Conclusions}

According to analysis study of building materials, the mosque was built from three types of raw materials: sandstone at external wall, bricks at internal wall and the columns cut from marble. Lime mortar was used as joint mortar and plaster.

Field observation confirmed a lot of weathering forms that effected on building materials at Helal mosque. Most of current deterioration and damage conditions were mainly due to: aggressive environmental condition, old restoration with Portland cement mortar and age of the building. More cracks were found at the façade. It required urgent treatment and conservation to avoid a lot of damage.

Architectural conservation of the mosque were carried out as restoration of the mosque ceiling in order to stabilize the conservation state of the mosque.

The importance in this restoration project was the discovering of very fine Islamic decoration at the mosque 


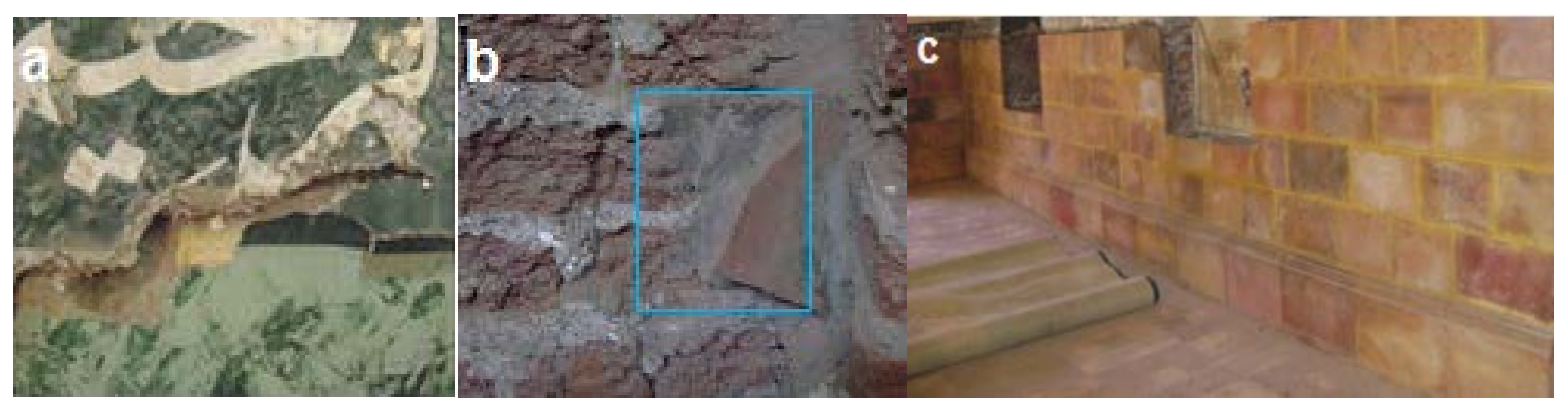

Figure 22. Casing the inner walls of the mosque of brick with sandstone tiles as it was in ancient times. a-The walls covered with Portland cement and new paints; b-During removing the cement mortar, the old tiles of sandstone appeared under the cement; c-After restoration.

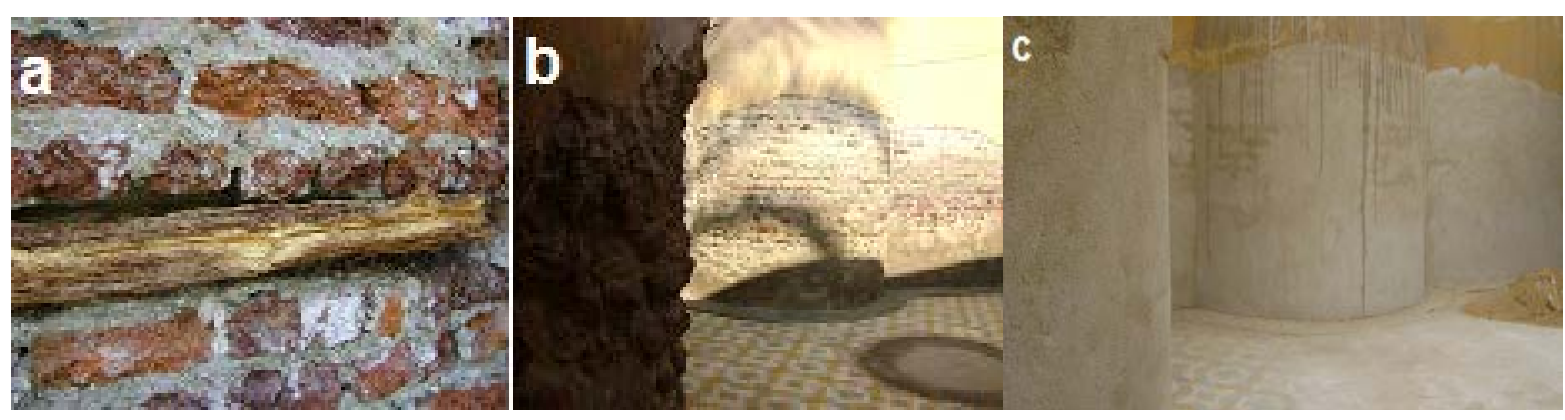

Figure 23. The restoration intervention at the brick walls. a, b-The brick wall after removing the deteriorated old mortar with salts; c-After restoration.

façade and around the mihrab that was covered with Portland cement mortar and lacquers in fault old restoration. In addition, the restoration process indicated that the lower part of interior brick walls was covered with sandstone tiles.

The missing parts of the artistic elements was completed by reproduction process and the fallen and missing blocks of stone had been replaced to compensate the loss of the deteriorated stone on the mosque.

Re-cladding the lower part of the brick walls by sandstone slabs was carried out.

Fine restoration was carried out at the façade that contained cleaning process, salt extraction, consolidation process and completion of missing parts.

\section{Acknowledgements}

The authors would like to thank Mr. Maher Soliman Ramadan and Mr. Ahmed Rashad Ahmed (conservators in Ministry of Archaeology) and the members of restoration of Islamic management at East Delta for helping in restoration process of Helal mosque.

\section{References}

[1] Bader, N.A. and Abdalla, E. (2013) Effects of the Groundwater on Deterioration of the Catacombs of Kom El-shoqafa, Alexandria, Egypt. E-Conservation, 25, 168-181. http://e-conservation.org/journal/current-issue

[2] Price, C.A. (1996) Stone Conservation, an Overview of Current Research. Getty Conservation Institute, Los Angles, 7-10.

[3] Bernard, MF. (2003) Conservation of Historic Buildings. 3rd Edition, Linacre House, Jordan Hill, Oxford, 170-175.

[4] Ghedini, N., Gobbi, G., Sabbioni, C. and Zappia, G., (2000) Determination of Elemental and Organic Carbon on Damaged Stone Monuments. Atmospheric Environment, 34, 4383-4391.

http://www.journals.elsevier.com/atmospheric-environment/

[5] Chin, Z. (2013) Conservation of Nam June Paik's 32 Cars for the $20^{\text {th }}$ Century: Play Mozart's Requiem Quietly. Proceedings of the Interim Meeting of the Modern Materials and Contemporary Art Working Group of ICOM-CC, Otterlo, 4-5 June 2013, 33-43. 
[6] Lukaszewich, J. (2004) The Efficiency of the Application of Tetraethoxysilane in the Conservation of Stone Monuments. Proceedings of the 10th International Congress on Deterioration and Conservation of Stone, Stockholm, 27 June-2 July 2004, 479-486.

[7] Bader, N.A. and Mahran, A. (2015) Restoration and Preservation of Artistic Elements Applied on Islamic Architectural Façade of Shahin Agha Sebil, Cairo, Egypt. International Journal of Conservation Science, 6, 63-78, http://www.ijcs.uaic.ro/

[8] Bader, N.A. (2000) Study of Conservation and Preservation of Mural Paintings Executed on a Sandstone Support for Bawitti Tombs Area, Bahria Oasis, Applied to One of Cemeteries. Master Thesis, Faculty of Archaeology, Restoration Department, Cairo University, 260-265.

[9] Abdullah, M.A., Marie, H. Mahmoud, H.A. and Ali, M.F. (2014) Technical Examination and Restoration of the Stucco Decorations of Al Hasawaty Mihrāb, Fatimid Period, Cairo, Egypt. IJCS, 5, 469-478. http://www.ijcs.uaic.ro/ 